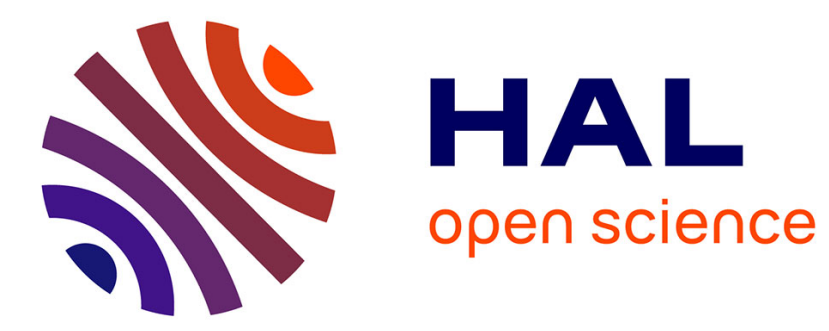

\title{
Eureka: A New 5-Degree-of-Freedom Redundant Parallel Mechanism with High Tilting Capabilities
}

Sébastien Krut, Olivier Company, François Pierrot

\section{To cite this version:}

Sébastien Krut, Olivier Company, François Pierrot. Eureka: A New 5-Degree-of-Freedom Redundant Parallel Mechanism with High Tilting Capabilities. IROS: Intelligent Robots and Systems, Oct 2003, Las Vegas, NV, United States. pp.3575-3580, 10.1109/IROS.2003.1249710 . lirmm-00191915

\section{HAL Id: lirmm-00191915 https://hal-lirmm.ccsd.cnrs.fr/lirmm-00191915}

Submitted on 26 Nov 2007

HAL is a multi-disciplinary open access archive for the deposit and dissemination of scientific research documents, whether they are published or not. The documents may come from teaching and research institutions in France or abroad, or from public or private research centers.
L'archive ouverte pluridisciplinaire HAL, est destinée au dépôt et à la diffusion de documents scientifiques de niveau recherche, publiés ou non, émanant des établissements d'enseignement et de recherche français ou étrangers, des laboratoires publics ou privés. 


\title{
Eureka: A New 5-Degree-of-Freedom Redundant Parallel Mechanism with High Tilting Capabilities
}

\author{
SÉBAstien Krut, Olivier COMPANy, SANi RANGSRi, François Pierrot \\ LIRMM, UMR 5506 CNRS-UM2 \\ 161, rue Ada, 34392 Montpellier Cedex 5, France \\ $<$ krut, company, rangsri, pierrot $>@$ lirmm.fr
}

\begin{abstract}
This paper introduces Eureka (see video), a new parallel mechanism providing five motions: three translations plus two rotations. This device is able to reach high tilting angles $\left( \pm 90^{\circ}\right.$ about a first given axis and a whole revolution about the following axis). This is due to actuation redundancy and to the specific traveling plate. Kinematic models are derived. Due to its particular shape the forward geometrical model is also derived easily. A plot of its well conditioned workspace is given. Practical designs, free of self-collisions, are shown.
\end{abstract}

\section{Introduction}

After Gough and Stewart in the 50's and 60's introducing the idea of so-called "hexapods", Clavel and his Delta structure [1] in the late 80 's opened a new era of PKM able to reach extremely high velocities and accelerations. In addition, mechanism stiffness is often very high compared to serial arms. Thus many PKM have been dedicated to pickand-place and more recently to machining.

But one of the PKM drawbacks is their limited workspace, especially the limitation of the ending part's tilting angle. Five different ways may be possible to compensate for this drawback:

- Sharing the degrees of freedom (dof) between a carrying structure and a wrist, as it is done by DS Technologies Inc. with Sprint (serial + parallel), or Neos Robotics with Tricept [2] (parallel + serial). Note that the wrist could even be itself parallel, for example based on Gosselin's Agile Eye concept [3];

- Designing machines using the "right-hand / left-hand" paradigm, where both the tool and the manufactured part are moving with respect to the ground, as it is done in classical machines with turning tables;

- Building redundant machines, that is to say over-actuated ones, like the Eclipse [4] machine tool or the Archi [4] robot. The Eclipse is designed to achieve five faces milling and Archi is a planar 3 degrees-of-freedom robot that allows an infinite rotation about one axis;

- Building motion transformation systems located on the traveling plate to increase tilting angles of existing machines. The principle of Twice mechanism [6] illustrates such an idea. A simpler case is the $\mathrm{H} 4$ or the I4 robot [7] where the traveling plate is composed of two (or three) parts, a few simple joints (e.g. two pivot joints), and a gear amplification system for one rotational motion.

This paper is focused on the problem of 5-dof parallel mechanisms which has already been addressed in the past but by few researchers only. In addition to the 5-dof version of Tricept, few hybrid 5-dof machines have been proposed such as GeorgV [8] or Dumbo [9]; the architecture proposed by Zamanov [10] is radically different from the previous one since it is a fully-parallel mechanism based on 5 telescopic legs. One interesting approach has been followed by Stocco in [11]: the machine can be regarded has made of two subparts holding the traveling plate.

This paper introduces a novel mechanical architecture which combines two of the previous features: Eureka, the proposed machine is redundant (6 motors for 5 dof provide actuation redundancy) and it is based on a three-part traveling plate with two linear joints. The machine offers 3 translations and 2 rotations with large tilting capabilities in both directions; the first axis of rotation has a constant direction with respect to a fixed frame, the second axis is orthogonal to the first one.

A detailed kinematic analysis is carried out and leads to geometrical conditions to be verified by the mechanism for proper functioning. Then a kinematic modeling illustrates the mechanism simplicity and provides a first evaluation of the machine workspace. Finally, preliminary information is given regarding practical implementation of this new architecture.

\section{General Concept}

Eureka, the proposed machine is a 6-actuator / 5-dof parallel mechanism. In Fig. 1, a joint-and-loop graph is depicted: P, R, S and U stand for Prismatic, Revolute, Spherical and Universal joints. Gray boxes represent actuated joints; white boxes passive joints. Underlined letter stands for a joint equipped with a position sensor. Circles express a kinematic coupling between two joints.

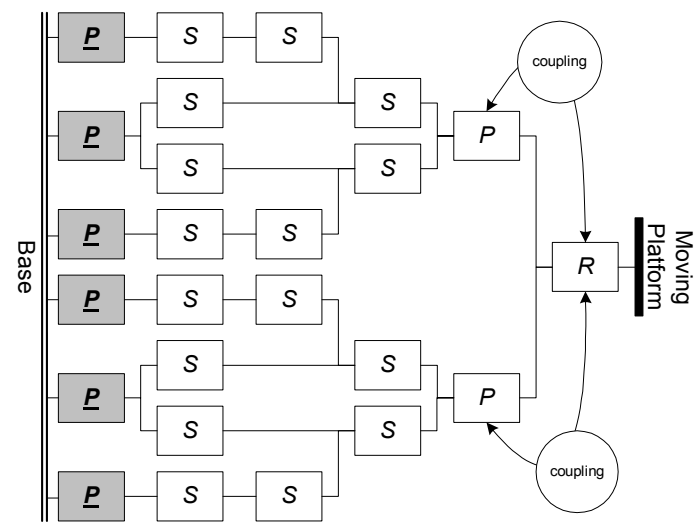

Fig. 1 - Joint-and-loop graph 
As for Delta and H4 architectures, the actuators are fixed on the base to reduce moving parts' masses. As for Delta and $\mathrm{H} 4$, motors may be rotational or linear, the ball joints may be replaced by U-joints (to get rid of internal motions). One must notice the machine's symmetrical architecture: the machine's upper and lower parts are identically made of a "spatial-parallelogram" and two single rods. Each single rod is connected to "spatial parallelograms".

Note that, in general, the "spatial-parallelogram" chains (that is: $\mathbf{P}(\mathrm{SS})_{2}$ chains) implement only one constraint on a mechanism ( 3 translations and 2 rotations remain feasible); would a "spatial-parallelogram" be made of $\underline{\mathbf{P R}}(\mathrm{RR})_{2} \mathrm{R}$ chains (as done on the Orthoglide [12]) it will implement two constraints on a mechanism ( 3 translations and 1 rotation remain feasible).

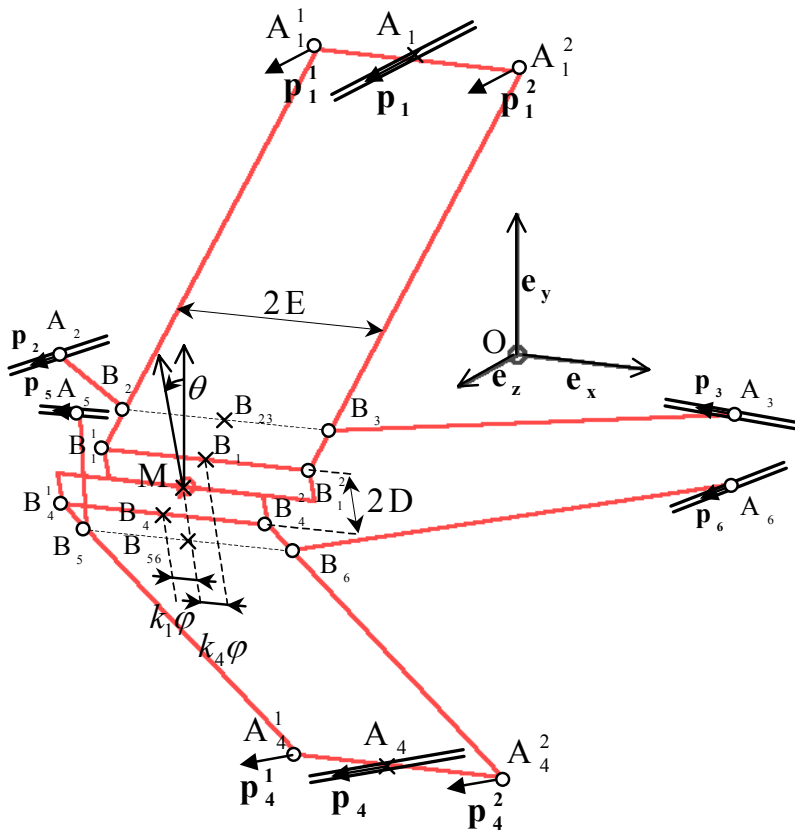

Fig. 2 - Kinematics scheme

The traveling plate is the one introduced in [7] with the I4 robot: while two sub-parts shift relatively one to the other, a mechanical device transforms this motion into a rotation. Two types of traveling plates exist (see Fig. 3): Type 1 is made of two prismatic joints and two kinematically coupled rack-and-pinion systems. Type 2 is made up with one part less, but looses Type 1 symmetrical design (good for balancing load among the parts).

To further describe the mechanism, it is necessary to resort to a few notation:

- The ratio $f(0 \leq f \leq 1)$ determines the point where the single rod is attached:

$$
\begin{gathered}
\mathbf{B}_{\mathbf{i}}=\mathbf{B}_{\mathbf{j}}^{\mathbf{k}}+f\left(\mathbf{A}_{\mathbf{j}}^{\mathbf{k}}-\mathbf{B}_{\mathbf{j}}^{\mathbf{k}}\right), \\
\text { for }(\mathrm{i}, \mathrm{j}, \mathrm{k}) \in\{(2,1,1),(3,1,2),(5,4,1),(6,4,2)\} .
\end{gathered}
$$

- The mathematical formalism developed in this paper can cope with both types of traveling plates. In fact if we note
$\mathbf{M}=\left(\begin{array}{lll}x & y & z\end{array}\right)^{\mathbf{T}}$ the vector associated to the operational point, and $\mathbf{R}$ the matrix representing the rotation of angle $\theta$ about $\mathbf{e}_{\mathbf{x}}$ :

$$
\mathbf{R}=\left(\begin{array}{ccc}
1 & 0 & 0 \\
0 & \cos (\theta) & -\sin (\theta) \\
0 & \sin (\theta) & \cos (\theta)
\end{array}\right),
$$

than:

$$
\begin{aligned}
& \mathbf{B}_{1}=\mathbf{M}+\mathbf{R}\left(\begin{array}{lll}
k_{1} \varphi & D & 0
\end{array}\right)^{\mathbf{T}}, \\
& \mathbf{B}_{4}=\mathbf{M}+\mathbf{R}\left(\begin{array}{lll}
k_{4} \varphi & -D & 0
\end{array}\right)^{\mathbf{T}},
\end{aligned}
$$

with:

$-k_{4}=-k_{1}$ for traveling plate type 1 ,

- $k_{4}=0$ for traveling plate type 2 .

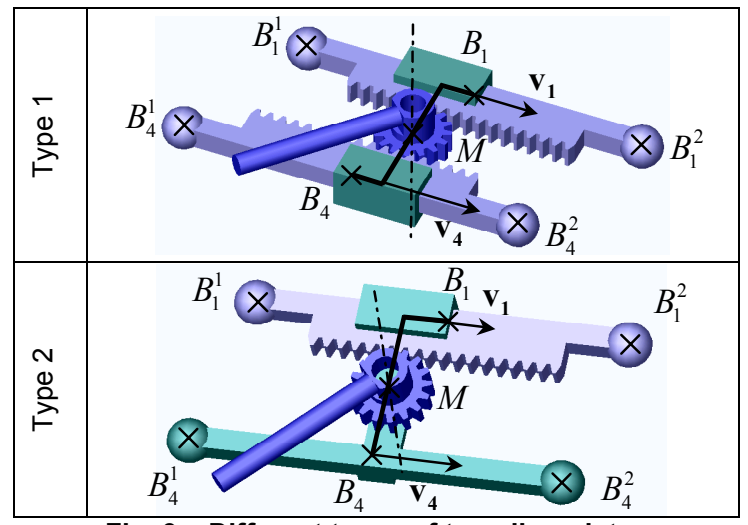

Fig. 3 - Different types of traveling plates

\section{Mechanisms Motions}

In this section the geometrical conditions that must be fulfilled in order to guarantee a non-singular design for the mechanism are described. A first emphasis is made on the "spatial parallelograms" because their design is responsible of the traveling plate's rotations; then the interest of the single rods for the "good" posture of parallelograms is shown.

Each traveling plate's lateral part is connected to a Deltalike "spatial parallelogram" by ball joints. Let us note $\mathbf{n}_{\mathbf{i}}^{\mathbf{j}}$ the vector joining $A_{i}^{j}$ to $B_{i}^{j}, i \in\{1,2\} \quad n_{i}$ the vector joining $A_{i}$ to $B_{i}$, and $\mathbf{u}_{i}$ the vector joining $B_{i}^{1}$ to $B_{i}^{2}$ (see Fig. 4).

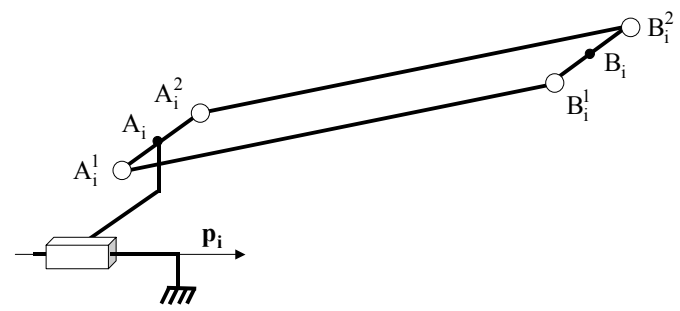

Fig. 4 - $\underline{P}(\mathrm{SS})_{2}$ chain

Velocity of point $A_{i}^{j}$ can be written as follows: 


$$
\mathbf{V}_{\mathbf{A}_{\mathbf{i}}^{\mathbf{j}}}=\dot{q}_{i} \mathbf{p}_{\mathbf{i}}^{\mathbf{j}}, i \in\{1,4\}, j \in\{1,2\},
$$

where $\mathbf{p}_{i}^{\mathrm{j}}$ is a vector tangent to point $\mathrm{A}_{\mathrm{i}}^{\mathrm{j}}$ trajectory. For linear motors this vector is unitary, for rotational motors, its norm is equal to the distance of point $\mathrm{A}_{\mathrm{i}}^{\mathrm{j}}$ to the rotational axis. Such an expression is also true for single rods:

$$
\mathbf{V}_{\mathbf{A}_{\mathbf{i}}}=\dot{q}_{i} \mathbf{p}_{\mathbf{i}}, i \in\{2,3,5,6\} \text {. }
$$

$\dot{q}_{i}$ can be expressed relatively to $\mathrm{B}_{\mathrm{i}}^{\mathrm{j}}$ by resorting to the rigid body's velocity property:

$$
\mathbf{V}_{\mathbf{A}_{\mathrm{i}}^{\mathrm{j}}}^{\mathrm{T}} \mathbf{n}_{\mathrm{i}}^{\mathrm{j}}=\mathbf{V}_{\mathbf{B}_{\mathrm{i}}^{\mathrm{j}}}^{\mathrm{T}} \mathbf{n}_{\mathrm{i}}^{\mathrm{j}},
$$

it leads to:

$$
\dot{q}_{i}=\frac{\mathbf{V}_{\mathbf{B}_{i}^{\mathbf{j}}}{ }^{\mathbf{T}} \mathbf{n}_{\mathbf{i}}^{\mathbf{j}}}{\left(\mathbf{p}_{\mathbf{i}}^{\mathbf{j}}\right)^{\mathbf{T}} \mathbf{n}_{\mathbf{i}}^{\mathbf{j}}}
$$

Assuming that $\mathbf{V}_{\mathbf{M}}{ }^{1}$ is the velocity of point $\mathbf{M}, \boldsymbol{\omega}$ the rotation velocity of the end-effector, and that $v_{i} \mathbf{v}_{\mathbf{i}}$ is the linear velocity of $\mathrm{B}_{\mathrm{i}}^{\mathrm{j}}$ relative to the traveling plate central part, $i \in\{1,4\}, j \in\{1,2\}$, velocity of point $\mathrm{B}_{\mathrm{i}}^{\mathrm{j}}$ can be written as follows ( $\times$ represents the cross product):

$$
\mathbf{V}_{\mathbf{B}_{\mathbf{i}}^{\mathbf{j}}}=\mathbf{V}_{\mathbf{M}}+\boldsymbol{\omega} \times \mathbf{s}_{\mathbf{i}}^{\mathbf{j}}+v_{i} \mathbf{v}_{\mathbf{i}}, i \in\{1,4\}, j \in\{1,2\},
$$

where:

- $\mathbf{s}_{\mathbf{i}}^{\mathbf{j}}$ is the vector joining $M$ to $B_{i}^{\mathrm{j}}$,

- $\mathbf{v}_{\mathbf{1}}$ and $\mathbf{v}_{\mathbf{4}}$ are unitary vectors aligned with the traveling plate guide ways (see Fig. 3).

Deriving (1) leads to velocities of points $B_{i}$ :

$$
\mathbf{V}_{\mathbf{B}_{\mathbf{i}}}=(1-f) \mathbf{V}_{\mathbf{B}_{\mathbf{j}}^{k}}+f \mathbf{V}_{\mathbf{A}_{\mathbf{j}}^{k}}
$$

$$
\text { for }(\mathrm{i}, \mathrm{j}, \mathrm{k}) \in\{(2,1,1),(3,1,2),(5,4,1),(6,4,2)\} \text {. }
$$

Taking into account (5) and (8) implies that:

$$
\mathbf{V}_{\mathbf{B}_{\mathbf{i}}}{ }^{\mathrm{T}} \mathbf{n}_{\mathbf{i}}=(1-f) \mathbf{V}_{\mathbf{B}_{\mathbf{j}}^{\mathbf{k}}}{ }^{\mathrm{T}} \mathbf{n}_{\mathbf{i}}+f{ }_{j}^{k} r_{i} \mathbf{V}_{\mathbf{B}_{\mathbf{j}}^{\mathbf{k}}}^{\mathrm{T}} \mathbf{n}_{\mathbf{j}}^{\mathbf{k}},
$$

where:

$$
{ }_{j}^{k} r_{i}=\frac{\left(\mathbf{p}_{\mathbf{j}}^{\mathbf{k}}\right)^{\mathbf{T}} \mathbf{n}_{\mathbf{i}}}{\left(\mathbf{p}_{\mathbf{j}}^{\mathbf{k}}\right)^{\mathbf{T}} \mathbf{n}_{\mathbf{j}}^{\mathbf{k}}},
$$

for $(\mathrm{i}, \mathrm{j}, \mathrm{k}) \in\{(2,1,1),(3,1,2),(5,4,1),(6,4,2)\}$.

(11) can be rewritten as follows:

$$
\mathbf{n}_{\mathrm{i}}{ }^{\mathrm{T}} \mathbf{V}_{\mathbf{B}_{\mathrm{i}}}={ }_{\mathrm{j}}^{\mathrm{k}} \mathbf{n}_{\mathrm{i}}{ }^{\mathrm{T}} \mathbf{V}_{\mathrm{B}_{\mathrm{j}}^{\mathrm{k}}},
$$

with:

$$
{ }_{\mathbf{j}}^{\mathbf{k}} \mathbf{n}_{\mathbf{i}}=(1-f) \mathbf{n}_{\mathbf{i}}+f{ }_{j}^{k} r_{i} \mathbf{n}_{\mathbf{j}}^{\mathbf{k}} .
$$

By using the rigid body's velocity property applied to all rods, the following set of equations is obtained:

$$
\mathbf{M}_{1}\left(\mathbf{V}_{\mathbf{M}}{ }^{\mathrm{T}} \quad \boldsymbol{\omega}^{\mathrm{T}} \quad v_{1} \quad v_{2}\right)^{\mathbf{T}}=\mathbf{N}_{\mathbf{1}} \dot{\mathbf{q}},
$$

with:

$\left.{ }^{1} \mathbf{V}_{\mathrm{Pt}_{\mathrm{t}}}=\dot{\mathbf{P} \mathbf{t}}=\frac{d \mathbf{P} \mathbf{t}}{d t}\right)_{\Re}$

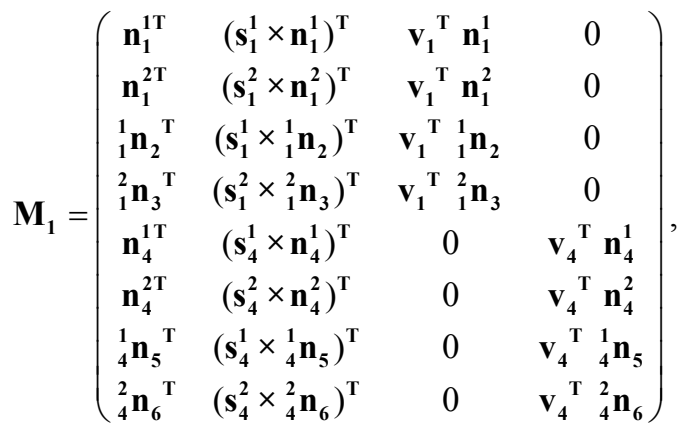

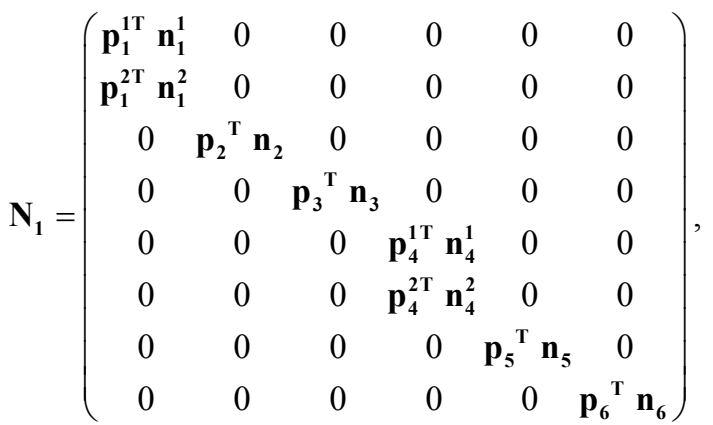

and:

$$
\dot{\mathbf{q}}=\left(\begin{array}{llllll}
\dot{q}_{1} & \dot{q}_{2} & \dot{q}_{3} & \dot{q}_{4} & \dot{q}_{5} & \dot{q}_{6}
\end{array}\right)^{\mathbf{T}} .
$$

Assuming that, when the mechanism is assembled $\mathbf{n}_{\mathbf{i}}^{1}=\mathbf{n}_{\mathbf{i}}^{2}=\mathbf{n}_{\mathbf{i}}, \mathbf{p}_{\mathbf{i}}^{1}=\mathbf{p}_{\mathbf{i}}^{2}=\mathbf{p}_{\mathbf{i}}$, by subtracting line 1 with 2 , line 4 with 5 , system (15) can be written:

$$
\mathbf{M}_{2}\left(\begin{array}{llll}
\mathbf{V}_{\mathbf{M}}{ }^{\mathbf{T}} & \boldsymbol{\omega}^{\mathbf{T}} & v_{1} & v_{2}
\end{array}\right)^{\mathbf{T}}=\mathbf{N}_{2} \dot{\mathbf{q}},
$$

with:

$$
\mathbf{M}_{2}=\left(\begin{array}{cccc}
\mathbf{n}_{1}{ }^{\mathrm{T}} & \left(\mathbf{s}_{1}^{1} \times \mathbf{n}_{1}\right)^{\mathrm{T}} & \mathbf{v}_{1}{ }_{1}^{\mathrm{T}} \mathbf{n}_{1} & 0 \\
{ }_{1}^{1} \mathbf{n}_{2}{ }^{\mathrm{T}} & \left(\mathbf{s}_{1} \times \times{ }_{1} \mathbf{n}_{2}\right)^{\mathrm{T}} & \mathbf{v}_{1}{ }_{1}{ }_{1} \mathbf{n}_{2} & 0 \\
{ }_{1}^{2} \mathbf{n}_{3}{ }^{\mathrm{T}} & \left(\mathbf{s}_{1} \times{ }_{1}{ }_{1} \mathbf{n}_{3}\right)^{\mathrm{T}} & \mathbf{v}_{1}{ }^{\mathrm{T}}{ }_{1}^{2} \mathbf{n}_{3} & 0 \\
\mathbf{n}_{4}{ }^{\mathrm{T}} & \left(\mathbf{s}_{4} \times \mathbf{n}_{4}{ }^{\mathrm{T}}\right)^{\mathrm{T}} & 0 & \mathbf{v}_{4}{ }^{\mathrm{T}} \mathbf{n}_{4} \\
{ }_{4}^{1} \mathbf{n}_{5}{ }^{\mathrm{T}} & \left(\mathbf{s}_{4}^{1} \times{ }_{4}^{1} \mathbf{n}_{5}\right)^{\mathrm{T}} & 0 & \mathbf{v}_{4}{ }^{\mathrm{T}}{ }_{4} \mathbf{n}_{5} \\
{ }_{4}^{2} \mathbf{n}_{6}{ }^{\mathrm{T}} & \left(\mathbf{s}_{4} \times{ }_{4}{ }_{4} \mathbf{n}_{6}\right)^{\mathrm{T}} & 0 & \mathbf{v}_{4}{ }^{\mathrm{T}}{ }_{4} \mathbf{n}_{6} \\
\mathbf{0}^{\mathrm{T}} & \left(\mathbf{u}_{1} \times \mathbf{n}_{1}\right)^{\mathrm{T}} & 0 & 0 \\
\mathbf{0}^{\mathrm{T}} & \left(\mathbf{u}_{4} \times \mathbf{n}_{4}\right)^{\mathrm{T}} & 0 & 0
\end{array}\right),
$$

$$
\mathbf{N}_{2}=\left(\begin{array}{cccccc}
\mathbf{p}_{1}{ }^{\mathrm{T}} \mathbf{n}_{1} & 0 & 0 & 0 & 0 & 0 \\
0 & \mathbf{p}_{2}{ }^{\mathrm{T}} \mathbf{n}_{2} & 0 & 0 & 0 & 0 \\
0 & 0 & \mathbf{p}_{3}{ }^{\mathrm{T}} \mathbf{n}_{3} & 0 & 0 & 0 \\
0 & 0 & 0 & \mathbf{p}_{4}{ }^{\mathrm{T}} \mathbf{n}_{4} & 0 & 0 \\
0 & 0 & 0 & 0 & \mathbf{p}_{5}{ }^{\mathrm{T}} \mathbf{n}_{5} & 0 \\
0 & 0 & 0 & 0 & 0 & \mathbf{p}_{6}{ }^{\mathrm{T}} \mathbf{n}_{6} \\
0 & 0 & 0 & 0 & 0 & 0 \\
0 & 0 & 0 & 0 & 0 & 0
\end{array}\right)
$$

\subsection{Geometrical conditions regarding rotations}

In this section we derive the conditions to be fulfilled by the mechanism for guaranteeing that the traveling plate 
central part will exhibit a unique rotation about an axis with constant direction (with respect to the fixed frame): this is the traveling plate "own rotation". The second operational rotation will be provided by transforming the relative translation between the lateral parts and the central part into a rotation of the tool.

Noting $\mathbf{M}_{\mathbf{2}}=\left(\begin{array}{l}\mathbf{M}_{21} \\ \mathbf{M}_{22}\end{array}\right)$, where $\mathbf{M}_{22}$ is composed by the two last lines of $\mathbf{M}_{2}$, (same with $\mathbf{N}_{\mathbf{2}}=\left(\begin{array}{l}\mathbf{N}_{21} \\ \mathbf{N}_{\mathbf{2 2}}\end{array}\right)$ ) the following equation is obtained:

$$
\mathbf{M}_{22}\left(\begin{array}{llll}
\mathbf{V}_{\mathbf{M}}{ }^{\mathbf{T}} & \boldsymbol{\omega}^{\mathbf{T}} & v_{1} & v_{2}
\end{array}\right)^{\mathbf{T}}=\mathbf{0} .
$$

As all the elements of the three first columns of $\mathbf{M}_{22}$ are equal to zero, $\mathbf{V}_{\mathbf{M}}$ has no influence in equation (22). It's the same for the two columns regarding $v_{1}$ and $v_{2}$. This leads to an under-determined system ( 3 unknowns for 2 equations):

$$
\mathbf{M}_{\mathrm{un}} \boldsymbol{\omega}=\mathbf{0} \text {, }
$$

with :

$$
\mathbf{M}_{\mathrm{un}}=\left(\begin{array}{c}
\left(\mathbf{u}_{1} \times \mathbf{n}_{1}\right)^{\mathrm{T}} \\
\left(\mathbf{u}_{4} \times \mathbf{n}_{4}\right)^{\mathrm{T}}
\end{array}\right)
$$

\subsubsection{Geometrical condition to get the desired rotation}

We focus here on the traveling plate "own rotation" and in the following, it is decided that:

$$
\boldsymbol{\omega}=\omega_{x} \mathbf{e}_{\mathbf{x}}
$$

where $\boldsymbol{\omega}=\left(\begin{array}{lll}\omega_{x} & \omega_{y} & \omega_{z}\end{array}\right)^{\mathbf{T}}$.

Thus:

$$
\omega_{y}=\omega_{z}=0,
$$

A condition for system (23) to be true for every acceptable $\omega_{x}$ is:

$$
\mathbf{u}_{1}=\mathbf{u}_{4}=\mathbf{e}_{\mathbf{x}} .
$$

\subsubsection{Geometrical condition to get rid of inappropriate rotations}

A necessary condition for statement (26) is:

$$
\operatorname{det}\left(\begin{array}{ll}
\mathbf{M}_{\mathbf{u n}}(1,2) & \mathbf{M}_{\mathbf{u n}}(1,3) \\
\mathbf{M}_{\mathbf{u n}}(2,2) & \mathbf{M}_{\mathbf{u n}}(2,3)
\end{array}\right) \neq 0
$$

Noticing the determinant of this matrix is equal to the surface of the polygon made up with the row vectors of $\mathbf{M}_{\mathbf{u n}}$, this condition can be rewritten as follows:

$$
\left\|\left(\mathbf{e}_{\mathbf{x}} \times \mathbf{n}_{1}\right) \times\left(\mathbf{e}_{\mathbf{x}} \times \mathbf{n}_{\mathbf{4}}\right)\right\| \neq 0 .
$$

The practical design must then guarantee that $\mathbf{e}_{\mathbf{x}}$ and $\mathbf{n}_{\mathbf{i}}$, $i \in\{1,4\}$ never become parallel in the whole workspace (the same condition holds for $\mathbf{n}_{1}$ with $\mathbf{n}_{4}$ ).

\subsection{Geometrical conditions to obtain good placement of parallelograms}

By observing $\mathbf{N}_{2}$, it appears that the practical design must guarantee that $\mathbf{p}_{\mathbf{i}}$ and $\mathbf{n}_{\mathrm{i}}, \quad i \in\{1, \ldots, 6\}$ never get perpendicular in the whole workspace.

\section{$4 \quad$ Kinematic modeling}

In this section, relationships between actuators' and traveling plate's coordinates (represented by vector $\mathbf{q}=\left(\begin{array}{lll}q_{1} & \ldots & q_{6}\end{array}\right)^{\mathbf{T}}$ and $\left.\mathbf{x}=\left(\begin{array}{llllll}x_{M} & y_{M} & z_{M} & \theta & \varphi\end{array}\right)^{\mathbf{T}}\right)$ are derived. The relationship between actuators' and traveling plate's velocities, respectively represented by $\dot{\mathbf{q}}$ and $\dot{\mathbf{x}}$, is also presented.

\subsection{Relationship between $x$ and $q$}

\section{1) Inverse Position Relationship}

As it is usual for most parallel robots, the inverse position relationship is easy to compute. It is derived from the following equality:

$$
\left\|\mathbf{B}_{\mathbf{i}}-\mathbf{A}_{\mathbf{i}}\right\|^{2}=l_{i}^{2}, \mathrm{i} \in\{1, \ldots, 6\},
$$

where $l_{i}$ is the length of the $i^{\text {th }}$ rod. This can be derived for linear motors as well as for rotational motors (see for example in [14]).

\section{2) Forward Position Relationship}

A nice feature of this machine is that an analytic forward position relationship can be derived. In fact knowing the positions of the 3 upper-part actuators (respectively lowerpart), point $\mathrm{B}_{23}$ can be determined easily (respectively $\mathrm{B}_{56}$ ). This can be done, for example, by computing the intersection of three spheres.

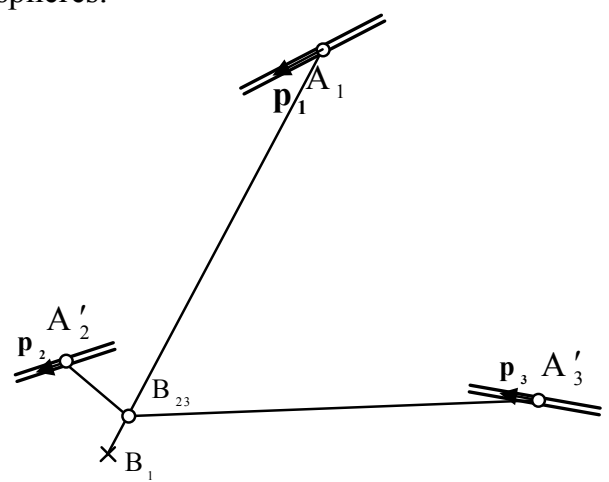

Fig. 5 - Simplified scheme of the upper part.

Then, with geometrical considerations, points $B_{1}$ and $B_{4}$ are derived:

$$
\mathbf{B}_{1}=\frac{\mathbf{B}_{23}-f \mathbf{A}_{1}}{1-f}, \mathbf{B}_{4}=\frac{\mathbf{B}_{56}-f \mathbf{A}_{4}}{1-f} .
$$

Let us note $\mathbf{s}_{\mathbf{1 4}}$ the vector going from $B_{1}$ to $B_{4}$ $\left(\mathbf{s}_{14}=\mathbf{B}_{4}-\mathbf{B}_{1}\right)$, then point $\mathrm{M}$ 's coordinates can be written as follows: 


$$
\mathbf{M}=\mathbf{B}_{1}+\left(\frac{-k_{1}}{k_{4}-k_{1}} \mathbf{s}_{14}{ }^{\mathrm{T}} \mathbf{e}_{\mathbf{x}} \quad \frac{1}{2} \mathbf{s}_{14}{ }^{\mathrm{T}} \mathbf{e}_{\mathbf{y}} \quad \frac{1}{2} \mathbf{s}_{14}{ }^{\mathrm{T}} \mathbf{e}_{\mathbf{z}}\right)^{\mathrm{T}}
$$

It leads that the operational vector $\mathbf{x}$ can be expressed as follows:

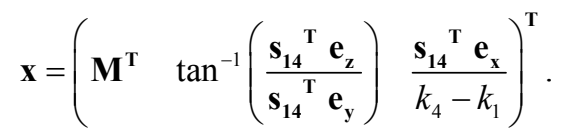

Note that for a parallel mechanism with actuation redundancy, computing the operational coordinates when the actuators position are known, can be done in several ways because the joint position vector is of greater dimension than the operational position vector.

\subsection{Relationship between $\dot{x}$ and $\dot{q}$}

This relationship can be written in the following form, resorting to matrices $\mathbf{J}_{\mathbf{x}}$ and $\mathbf{J}_{\mathbf{q}}$ :

$$
\mathbf{J}_{\mathbf{x}} \quad \dot{\mathbf{x}}=\mathbf{J}_{\mathbf{q}} \quad \dot{\mathbf{q}} .
$$

It is worth noting that $\boldsymbol{\omega}=\dot{\theta} \mathbf{e}_{\mathbf{x}}$, and then to introduce the following matrix:

$$
\mathbf{L}=\left(\begin{array}{cccccccc}
1 & 0 & 0 & 0 & 0 & 0 & 0 & 0 \\
0 & 1 & 0 & 0 & 0 & 0 & 0 & 0 \\
0 & 0 & 1 & 0 & 0 & 0 & 0 & 0 \\
0 & 0 & 0 & 1 & 0 & 0 & 0 & 0 \\
0 & 0 & 0 & 0 & 0 & 0 & -k_{1} & k_{4}
\end{array}\right)^{\mathbf{T}},
$$

which satisfies the following equality:

$$
\left(\begin{array}{llll}
\mathbf{V}_{\mathbf{M}}{ }^{\mathbf{T}} & \boldsymbol{\omega}^{\mathbf{T}} & v_{1} & v_{2}
\end{array}\right)^{\mathbf{T}}=\mathbf{L} \dot{\mathbf{x}}
$$

Thus, considering (19) and (36) leads to:

$$
\begin{gathered}
\mathbf{J}_{\mathbf{x}}=\mathbf{M}_{\mathbf{2}} \mathbf{L}, \\
\mathbf{J}_{\mathbf{q}}=\mathbf{N}_{\mathbf{2}} .
\end{gathered}
$$

\subsection{Workspace analysis}

In this paper the focus is put on one particular design, where six linear motors are all directed by $\mathbf{e}_{\mathbf{z}}$ : this guarantees a large workspace in this particular direction. The representative vectors of the linear motor guide ways origins $\mathrm{O}_{\mathrm{i}}, \mathrm{i} \in\{1, \ldots, 6\}$, are:

$$
\begin{gathered}
\mathbf{O}_{1}=\left(\begin{array}{lll}
0 & J & 0
\end{array}\right)^{\mathbf{T}}, \mathbf{O}_{2}=\left(\begin{array}{lll}
-H & I & 0
\end{array}\right)^{\mathbf{T}}, \\
\mathbf{O}_{3}=\left(\begin{array}{lll}
H & I & 0
\end{array}\right)^{\mathbf{T}}, \mathbf{O}_{4}=\left(\begin{array}{lll}
0 & -J & 0
\end{array}\right)^{\mathbf{T}}, \\
\mathbf{O}_{5}=\left(\begin{array}{lll}
-H & -I & 0
\end{array}\right)^{\mathbf{T}}, \mathbf{O}_{6}=\left(\begin{array}{lll}
H & -I & 0
\end{array}\right)^{\mathbf{T}},
\end{gathered}
$$

where $H, I, J$ are geometrical parameters selected as follows:

$$
H=0.45 \mathrm{~m}, I=0.08 \mathrm{~m} \text { and } J=0.4 \mathrm{~m} .
$$

The traveling plate is of type $1\left(k_{4}=-k_{1}\right)$. Geometrical parameters' values are:

$$
D=0.05 \mathrm{~m}, E=0.06 \mathrm{~m} \text { and } k_{1}=-0.05 \mathrm{~m} / \mathrm{rad} \text {. }
$$

Note that the amplification ratio $\left|k_{1}\right|$ is chosen equal to $D$ in order to have same rotations capabilities for $\theta$ and $\varphi$.

Length of rods and ratio $f$ are:

$$
l_{i}=0.9 \mathrm{~m}, i \in\{1, \ldots, 6\} \text { and } f=1 / 8 .
$$

Actuators limits are:

$$
0 \leq q_{i} \leq 1.26 \mathrm{~m} .
$$

The workspace is drawn taking into account:

- the actuators limits,

- the conditioning number of the normalized Jacobean matrix.

In fact, because $\mathbf{J}_{\mathbf{x}}$ is not homogenous ("mixing meter and radian") we decided to use the matrix normalization technique proposed in [13], which resorts to matrix $\mathbf{W}_{\mathbf{x}}$ $\left(\tilde{\dot{\mathbf{x}}}=\mathbf{W}_{\mathbf{x}} \dot{\mathbf{x}}\right)$ to obtain an operational vector $\tilde{\dot{\mathbf{x}}}$ only dealing with meters:

$$
\mathbf{W}_{\mathbf{x}}=\operatorname{diag}\left(\begin{array}{lllll}
1 & 1 & 1 & D & \left|k_{1}\right|
\end{array}\right) .
$$

$D$ and $\left|k_{1}\right|$ represent the characteristic lengths of the mechanism relative to $\theta$ and $\varphi$. They fix the ratio between maximum linear and angular velocities.

(34) implies that:

$$
\dot{\mathbf{q}}=\mathbf{J}_{\mathbf{q}}{ }^{-1} \mathbf{J}_{\mathbf{x}} \mathbf{W}_{\mathbf{x}}{ }^{-1} \tilde{\dot{\mathbf{x}}} .
$$

Fig. 6 presents the domain where the condition number of the normalized Jacobean matrix is smaller than 8 (note that along $z$ direction, the workspace is only limited by the actuators' range).

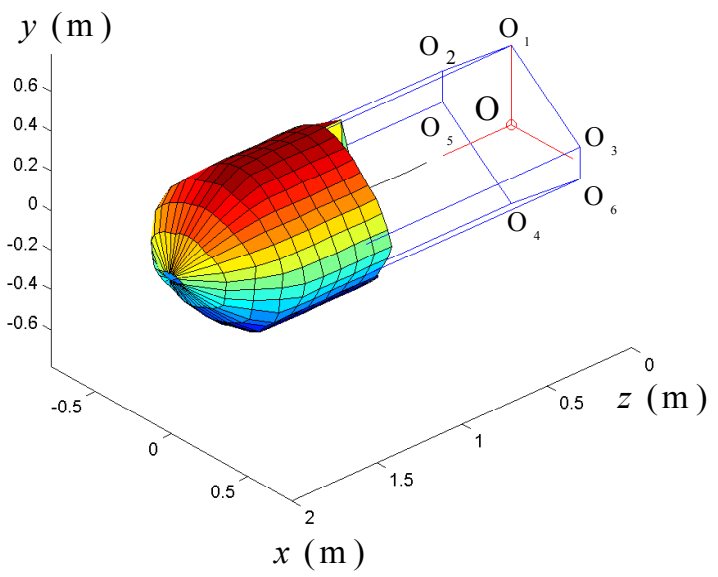

Fig. 6 - Workspace for cond $\left(J_{q}^{-1} J_{x} W_{x}^{-1}\right)<8$

\section{Practical design considerations}

In principle, it could be interesting for simplicity to directly connect the "single rods" to the traveling plate; however, such a practical design faces too many selfcollisions.

A more realistic design is obtained when the following condition is fulfilled: 


$$
f>2 D / l_{i}, i \in\{1,4\} .
$$

The machine depicted in Fig. 7 shows such a practical design. Another architecture avoiding self-collisions in shown in Fig. 8. In this case $f=0$, but single rods have a curved shape.

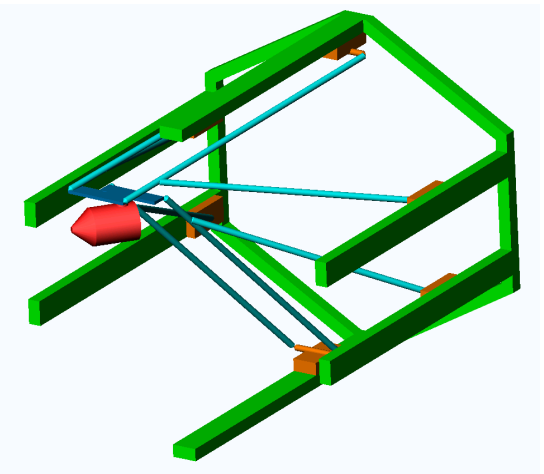

Fig. 7 - Self-collision-free design \#1

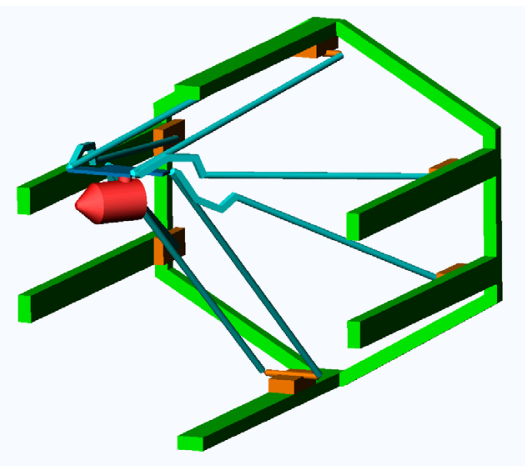

Fig. 8 - Self-collision-free design \#2

\section{Prototype design}

A prototype is about to be built. The practical design is extremely simple thanks to Linear motors (Fig. 9).

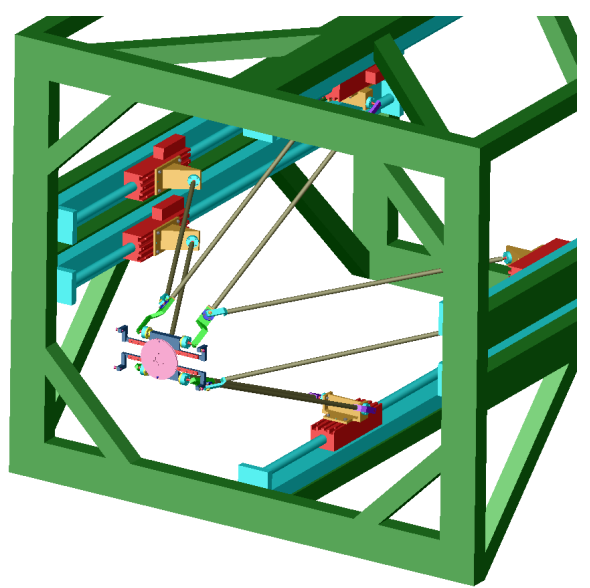

Fig. 9-CAD View of the Eureka prototype

Dimensions are the ones introduced for computing the workspace. Rods and traveling plate are made of aluminum. Spherical joints are new passive joints made by Ephaist Company (Japan). Instead of using rack-and-pinion systems, the mobile platform has been equipped with cable-pulley devices.

\section{Conclusion}

In this paper, Eureka a novel architecture has been introduced combining actuation redundancy and a three-part traveling plate. It has been shown that, if some geometrical constraints are satisfied, this architecture offers (i) a huge range of motion in rotation and translation, (ii) compact and simple kinematic modeling for control purposes, (iii) several realistic practical designs.

\section{References}

[1] R. Clavel, "Une nouvelle structure de manipulateur parallèle pour la robotique légère", $A P I I, 1989$, pp. 501-519.

[2] B. Siciliano, "The Tricept Robot: Inverse kinematics, manipulability analysis and closed-loop direct kinematics algorithm", Robotica, 1999, pp. 437-445.

[3] C.M. Gosselin, E. St-Pierre and M. Gagné, "On the development of the agile eye: mechanical design, control issues and experimentation", IEEE Robotics and Automation Society Magazine, Vol. 3, No. 4, 1996, pp. 29-37.

[4] S.J. Ryu, J.W. Kim, J.C. Hwang, C. Park, H.S. ho, K. Lee, Y. Lee, U. Cornel, F.C. Park and J. Kim, "ECLIPSE: An Overactuated Parallel Mechanism for Rapid Machining", Proc. ASME Int. Mechanical Engineering Congress and Exposition, Vol. 8, USA, 1998, pp. 681-689.

[5] F. Marquet, S. Krut, O. Company, F. Pierrot, "Archi, a redundant mechanism for machining with unlimited rotation capacities", Proc. of ICAR 2001, Budapest, Hungary, Aug. 2001.

[6] S. Krut, O. Company , F. Marquet, F. Pierrot, "Twice: A Tilting Angle Amplification System for Parallel Robots", in IEEE Int. Conf. on Robotics and Automation, Washington, Washington D.C., USA, May 11-15, 2002, pp. 4108-4113.

[7] S. Krut, O. Company, M. Benoit, H. Ota, F. Pierrot, "I4: A New Parallel Mechanism for Scara Motions", to appear in Proc. of IEEE International Conference on Robotics and Automation, Taipei, Taiwan, May 2003.

[8] K. Tönshoff, H. Grendel, and R. Kaak, "A hybrid manipulator for laser machining", in First European-American Forum on Parallel Kinematic Machines, Milan, Aug. 31-Sept. 1, 1998.

[9] K. Tönshoff K. and al., "Modelling of error effects on the new hybrid kinematic DUMBO structure", in $3^{\text {rd }}$ Chemnitzer Parallelkinematik Seminar, Chemnitz, April 23-25, 2002, pp. 639-653.

[10] V.B. Zamanov and Z.M. Sotirov, "Parallel manipulators in robotics", in IMACS/SICE Int. Symp. on Robotics, Mechatronics, and Manufacturing Systems, Kobe, Sept. 16-20, 1992, pp. 409-418.

[11] L. Stocco and T. Salcudean, "A coarse-fine approach to forcereflecting hand controller design", in IEEE Int. Conf. on Robotics and Automation, Minneapolis, April 24-26, 1996, pp. 404-410.

[12] Chablat $\mathrm{D}$. et Wenger Ph, "Design of a Three-Axis Isotropic Parallel Manipulator for Machining Applications: The Orthoglide", Workshop on Fundamental Issues and Future Research Directions for Parallel Mechanisms and Manipulators, October 3-4, Québec, Québec, Canada, 2002.

[13] L. Stocco, S. E. Salcudean and F. Sassani, "Matrix Normalization for Optimal Robot Design", in Proc. of IEEE ICRA, Leuven, Belgium, May 16-21, 1998.

[14] Merlet J.-P. and Pierrot F., "Modélisation des robots parallèles", in Analyse et modélisation des robots manipulateurs, Lavoisier, ISBN 2-7462-0300-6, 2001, pp. 93-144. 